\title{
The influence of dimethoxy methane (DMM)/dimethyl carbonate (DMC) addition on premixed ethane/oxygen/argon flame
}

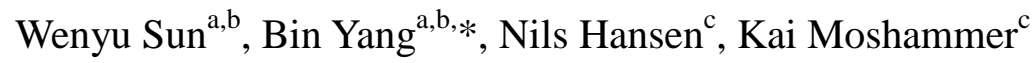 \\ ${ }^{a}$ Center for Combustion Energy and Department of Thermal Engineering, Tsinghua University, Beijing, 100084, P. \\ R. China \\ ${ }^{b}$ Key Laboratory for Thermal Science and Power Engineering of MOE, Tsinghua University, Beijing 100084, \\ China \\ ${ }^{c}$ Combustion Research Facility, Sandia National Laboratories, Livermore, CA 94551, USA
}

\section{Corresponding Author:}

Bin Yang

Center for Combustion Energy and Department of Thermal Engineering, Tsinghua University

Beijing 100084, P. R. China

Tel: +86-10-62796631

Fax: +86-10-62796631

E-mail: byang@tsinghua.edu.cn

\section{Colloquium: REACTION KINETICS}

Word Count (Method 1): The total word count (exclusive of title page, abstract) is: 6197 words

\section{Main text: $\quad \mathbf{3 5 4 2}$ words}

References: $\quad \mathbf{5 9 4}$ words (32 references)

Tables: 198 words (Table 1, 11 lines, 2 columns)

Figures: $\quad \mathbf{1 8 6 3}$ words (6 figures with captions)

\begin{tabular}{cccc}
\hline Figure & Column & Height $/ \mathrm{mm}$ & Word Count \\
\hline 1 & double & 118.8 & 563 \\
2 & single & 83.9 & 209 \\
3 & double & 85 & 418 \\
4 & singlet & 52.6 & 138 \\
5 & single & 63.8 & 162 \\
6 & single & 90 & 198 \\
Captions & & & 173 \\
\hline
\end{tabular}

*Corresponding author. E-mail: byang@ tsinghua.edu.cn, Tel: +86-10-62796631. 
Abstract: Two series of laminar premixed flames fueled by ethane-oxygenate-argon mixtures, in which ethane was incrementally replaced with either dimethoxy methane (DMM) or dimethyl carbonate (DMC) by mole fractions of $25 \%, 50 \%$ and $75 \%$, were investigated at a fixed carbon to oxygen ratio $(\mathrm{C} / \mathrm{O})$ of 0.50 and a pressure of 40 mbar. Mole fractions for flame species were obtained by employing molecular-beam mass spectrometry with synchrotron vacuum ultraviolet light for ionization. A detailed kinetic model including the chemistry of ethane, DMM and DMC was constructed and tested against the flame measurements. The effects of the addition of oxygenates to the species pool were studied, especially considering peak mole fractions of harmful emissions and relevant intermediates. The results indicate that the variation behaviors are mainly related to "volume effects" without strong chemical interactions between the fuel pairs. DMM and DMC show comparable performance in inhibiting soot precursors with the same addition amount. Formaldehyde is a major oxygenated emission in both flame series, almost linearly increasing with the addition of DMM or DMC, which is the consequence of the structural and kinetic characteristics of both oxygenates.

Keywords: Dimethoxy methane (DMM); Dimethyl carbonate (DMC); Flame intermediates; Blended fuel; Mass spectrometry 


\section{Introduction}

As renewable non-fossil fuels, oxygenated hydrocarbons are believed to produce less soot when compared to hydrocarbons under equivalent conditions [1, 2]. Because oxygenated fuels are commonly used as fuel additives, their soot-inhibition ability is usually influenced by both the chemistry of the base hydrocarbon fuels and the oxygenated additives as well as their chemical interactions. Considerable attention has been paid to this research field with the base fuel ranging from simple compounds like ethane [3], ethylene[4, 5], propene [6, 7] and 1,3-butadiene [8, 9], to larger ones such as heptane[10], benzene [11] and practical diesel fuels [12, 13]. It was reported in several engine studies $[12,13]$ that only the oxygen mass fraction of the fuel mixture affects the extent of soot reduction. However other considerable studies suggested that the molecular structures of added oxygenates $[1,6,14]$ also influence the extent of soot reduction. Other factors such as the initial $\mathrm{C} / \mathrm{O}$ ratio $[4,5,11]$ and the content of $\mathrm{C}-\mathrm{C}$ bonds in fuel mixtures [15] were also suggested to be relevant factors. Unfortunately, the benefit of such a soot reduction by oxygenated additives is achieved at the cost of an undesired and increased emission of toxic oxygenates like aldehydes and ketones $[2,6]$. The emissions are certainly the results of interactions among the whole reaction networks, which could be adjusted by altering the composition of fuel mixtures. A good understanding of the detailed combustion chemistry of newly proposed oxygenated fuels and blended fuels is therefore of great interest and is crucial in achieving a balanced soot and oxygenated emission [2].

In this study, two promising oxygenated additives, dimethoxy methane $\left(\mathrm{CH}_{3} \mathrm{OCH}_{2} \mathrm{OCH}_{3}\right.$, DMM), and dimethyl carbonate $\left[\mathrm{CH}_{3} \mathrm{OC}(=\mathrm{O}) \mathrm{OCH}_{3}, \mathrm{DMC}\right]$ were investigated, both being non-toxic and highly miscible with diesel fuels. Carbon-carbon $(\mathrm{C}-\mathrm{C})$ bonds are absent from the molecular 
structures of DMM and DMC. Their great soot-reduction potential can be expected due to their high mass fractions of oxygen ( 0.42 for DMM and 0.53 for DMC). The combustion kinetics of both DMM and DMC have been investigated in several previous studies [4, 5, 10, 16-19], however, the interactions with hydrocarbon fuels need to be further revealed from a perspective of kinetics. Ethane $\left(\mathrm{C}_{2} \mathrm{H}_{6}\right)$ was chosen as the base fuel enabling the investigation of the influences of C-C bonds to the reaction patterns of DMM and DMC. In this study, flames containing 0, 25, 50 and $75 \%$ $\mathrm{DMM}$ (or $\mathrm{DMC}$ ) with a fixed $\mathrm{C} / \mathrm{O}$ ratio of 0.50 were measured with photoionization mass spectrometry (PIMS). The variation range of the fuel composition is wide enough so that the gradual variation trends of species concentrations can be well captured. A kinetic model was constructed and validated against the experimental results. The experimental and modeling efforts were combined to elucidate the progressive changes in the species pool and the possible interactions between the base fuel and the respective oxygenated additives. The influence of the molecular structures of the oxygenated additives with regards to toxic emissions will also be discussed.

\section{Experimental Method}

The experimental work was performed at the Advanced Light Source (ALS) at the Lawrence Berkeley National Laboratory. The apparatus includes a McKenna-type burner, a molecular beam sampling system and a reflectron time-of-flight mass spectrometer (TOFMS). The synchrotron vacuum ultraviolet (VUV) light is used for ionization. Both are described in detail elsewhere [20, 21]. A total of eight flames, including a neat DMM flame, a base ethane flame and the blended series, were investigated in this study. Ethane in the base flame was replaced incrementally, from 25 mol\% up to $75 \mathrm{~mol} \%$, by either DMM or DMC with the $\mathrm{C} / \mathrm{O}$ ratio fixed at 0.50 . For all flames the total 
volume flow rate was kept at 4 standard liters per minute (SLM) with an argon dilution ratio of $25 \%$. The pressure was kept at 40 mbar (with an uncertainty of $\pm 1 \%$ ) to maximize the flame thickness and stand-off distance while maintaining flame stability. The detailed flame conditions are provided in Table 1. The gas flows $\left(\mathrm{O}_{2}\right.$, Ar and $\left.\mathrm{C}_{2} \mathrm{H}_{6}\right)$ were controlled separately by mass flow controllers, while the flow of liquid DMM or DMC was metered by a syringe pump before entering a vaporizer. Errors for all flow rates were estimated within $2 \%$ of the target values. Flame gases were sampled along the axis of the flames by a quartz cone of $0.25 \mathrm{~mm}$ orifice diameter and cone angle of $40^{\circ}$. The molecular beam from the sampling system was crossed by the dispersed VUV light from the monochromator and photo-ions were collected and mass-analyzed with the TOFMS which provides a mass resolution of $\mathrm{m} / \Delta \mathrm{m}$ up to 400 . The integrated ion intensities for a specific mass were normalized to the photon flux, and then plotted as a function of the photon energy or distance from the burner surface, which yielded photoionization efficiency (PIE) or mole fraction profiles, respectively. Flame temperature profiles were measured using laser-induced fluorescence (LIF) from $\mathrm{OH}$, as described by McIlroy et al. [22]. The uncertainty of the temperature measurement was estimated as $\pm 100 \mathrm{~K}[23]$. The temperature at the burner surface $(0 \mathrm{~mm})$ could not be experimentally determined and was estimated to be $500 \mathrm{~K}$. When performing model simulations, we followed the practice of shifting the measured temperature profiles by $1 \mathrm{~mm}$ downstream to compensate the probe effect [24].

The uncertainties for species mole fractions were estimated according to our recent study [19] of laminar premixed DMC flames under similar conditions. For major species the uncertainty factor $(U F)$ is estimated as 1.2 , increasing to 1.3 within the reaction zone (For the mole fraction $x$ of a certain species, the uncertainty range is between the upper limit of $x \cdot U F$ and the lower limit of 
$x / U F)$. For stable intermediates with measured photon ionization cross sections (PICSs), the $U F$ is within 1.7, and for radicals or species with estimated PICSs, the factors can be as large as 3-4. The estimated $U F \mathrm{~s}$ of the peak mole fractions for separate intermediates are provided in Table S1 together with the PICS and mass discrimination (MD) factors used in the data evaluation procedure. The measured mole fractions less than $1 \mathrm{~mm}$ away from the burner are not provided due to relatively severe sampling effects in this region [25].

All measured flame structures including temperature and species mole fraction profiles are provided in the Supplemental material. 


\section{Table 1}

Detailed flame conditions for all neat and blended flames

\begin{tabular}{|c|c|c|c|c|c|c|c|c|c|}
\hline \multirow{2}{*}{ No. } & \multirow{2}{*}{ Fuel composition } & \multirow{2}{*}{$\begin{array}{l}\text { Pressure } \\
\text { (mbar) }\end{array}$} & \multicolumn{5}{|c|}{ Volume flow rate (SLM) } & \multirow{2}{*}{$\mathrm{C} / \mathrm{O}$ ratio } & \multirow{2}{*}{$\begin{array}{l}\text { Equivalence } \\
\text { ratio }(\phi)\end{array}$} \\
\hline & & & $\mathrm{DMM}$ & $\mathrm{DMC}$ & $\mathrm{C}_{2} \mathrm{H}_{6}$ & $\mathrm{O}_{2}$ & $\mathrm{Ar}$ & & \\
\hline 1 & neat $\mathrm{C}_{2} \mathrm{H}_{6}$ & 40.0 & 0.00 & 0.00 & 1.00 & 2.01 & 1.00 & 0.50 & 1.74 \\
\hline 2 & neat DMM & 40.0 & 1.00 & 0.00 & 0.00 & 2.00 & 1.00 & 0.50 & 2.00 \\
\hline 3 & $25 \% \mathrm{DMM}+75 \% \mathrm{C}_{2} \mathrm{H}_{6}$ & 40.0 & 0.25 & 0.00 & 0.75 & 2.00 & 1.00 & 0.50 & 1.81 \\
\hline 4 & $50 \% \mathrm{DMM}+50 \% \mathrm{C}_{2} \mathrm{H}_{6}$ & 40.0 & 0.50 & 0.00 & 0.50 & 2.00 & 1.00 & 0.50 & 1.88 \\
\hline 5 & $75 \% \mathrm{DMM}+25 \% \mathrm{C}_{2} \mathrm{H}_{6}$ & 40.0 & 0.75 & 0.00 & 0.25 & 2.00 & 1.00 & 0.50 & 1.94 \\
\hline 6 & $25 \% \mathrm{DMC}+75 \% \mathrm{C}_{2} \mathrm{H}_{6}$ & 40.0 & 0.00 & 0.26 & 0.78 & 1.96 & 1.00 & 0.50 & 1.79 \\
\hline 7 & $50 \% \mathrm{DMC}+50 \% \mathrm{C}_{2} \mathrm{H}_{6}$ & 40.0 & 0.00 & 0.55 & 0.55 & 1.91 & 1.00 & 0.50 & 1.87 \\
\hline 8 & $75 \% \mathrm{DMC}+25 \% \mathrm{C}_{2} \mathrm{H}_{6}$ & 40.0 & 0.00 & 0.86 & 0.29 & 1.86 & 1.00 & 0.50 & 1.93 \\
\hline
\end{tabular}




\section{Kinetic modeling}

A detailed kinetic model was constructed by integrating the chemical kinetics of $\mathrm{C}_{2} \mathrm{H}_{6}, \mathrm{DMM}$ and DMC. The extensively validated $\mathrm{C}_{0}-\mathrm{C}_{4}$ mechanism AramcoMech1.3 [26] was employed as the core mechanism which includes reactions of crucial oxygenated intermediates in DMM and DMC combustion. The $\mathrm{C}_{5}-\mathrm{C}_{6}$ reactions, including benzene $\left(\mathrm{C}_{6} \mathrm{H}_{6}\right)$ formation pathways, were taken from a cyclohexane mechanism by Li et al. [27] in which the pressure-dependent rate coefficients of key reactions like the recombination of $\mathrm{C}_{3} \mathrm{H}_{3}$, conversions among $\mathrm{C}_{3}$ species $\left(\mathrm{C}_{3} \mathrm{H}_{4}, \mathrm{C}_{3} \mathrm{H}_{3}\right.$ and $\left.\mathrm{C}_{3} \mathrm{H}_{2}\right)$ and $\mathrm{C}_{4}+\mathrm{C}_{2}$ reactions were extracted from high-level theoretical works [28-31]. Besides, according to further model analysis, reactions related to the species $\mathrm{C}_{3} \mathrm{H}_{2}$ from [27] were added to the model and rate coefficients for the reaction pair of $\mathrm{C}_{3} \mathrm{H}_{3}+\mathrm{H}=\mathrm{C}_{3} \mathrm{H}_{4}-\mathrm{p} / \mathrm{C}_{3} \mathrm{H}_{4}$-a were updated with the calculations by Miller et al. [28]. The DMM sub-mechanism was taken from the kinetic model proposed by Glaude et al. [17], and the DMC sub-mechanism was originated from our recent study [19].

We ensured the consistency of thermochemical properties and transport data for all species before merging the abovementioned sub-mechanisms. 283 species and 1715 reactions are included in the entire model, which is provided in the Supplemental Material.

The simulations were performed using the Premixed code of Chemkin Pro software [32]. The measured temperature profiles were taken as input parameters. The multi-component transport and thermal diffusion were considered in the calculations.

\section{Results and discussion}

\subsection{Model validation}

The performance of the model was tested against all measured flame structures in the present study and the neat DMC flame reported in Ref. [19]. The agreements between experimental and simulated species mole fractions are satisfactory for all investigated flames. For examples, the major species $\left[\mathrm{CO}_{2}, \mathrm{CO}, \mathrm{H}_{2} \mathrm{O}, \mathrm{H}_{2}, \mathrm{Ar}, \mathrm{O}_{2}, \mathrm{C}_{2} \mathrm{H}_{6}, \mathrm{DMM}\right.$ (or DMC)] mole fraction profiles in the blended flames with 50\% DMM (or DMC) addition, including measurements and simulations, are 
presented in Fig. S1 in the Supplemental material. It can be noted that with the same addition amount of DMM and DMC, $\mathrm{CO}_{2}$ is produced at a much faster pace in the DMC blended flame. Simulated mole fraction distributions for main intermediates are compared with the corresponding measurements in these two blended flames with 50\% DMM (or DMC) addition, as demonstrated in Fig. 1. Both the shapes and the concentrations can be well captured by the current model, with the estimated uncertainties taken into account. Good agreement between experiments and simulations is also achieved in the neat flames $\left(\mathrm{C}_{2} \mathrm{H}_{6}\right.$ and DMM), as presented in Figs. S1-S2. The validated model was then used for the analysis of reaction pathways and further discussions of possible interactions within the species pool and reaction networks.
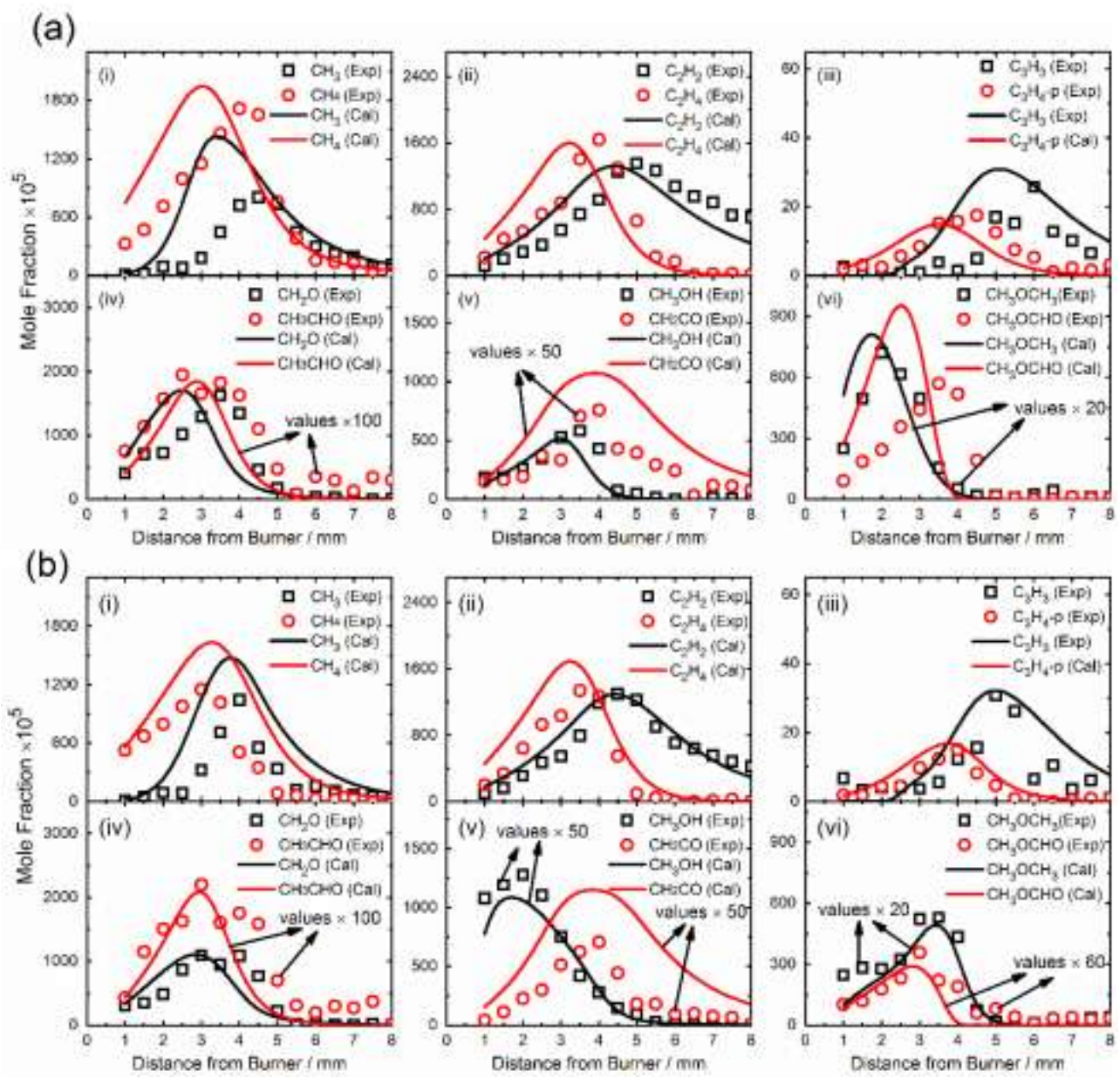

Fig. 1. Comparison between experimental and simulated mole fractions of main intermediates in (a) the $50 \% \mathrm{C}_{2} \mathrm{H}_{6}+50 \%$ DMM flame and (b) the $50 \% \mathrm{C}_{2} \mathrm{H}_{6}+50 \%$ DMC flame.

\subsection{Combustion characteristics and fuel consumption}

Insights into the changing species pool and the reaction networks can be gained through the 
combined experimental and modeling efforts. A previous study [23] suggested that mechanistic conclusions were unlikely to change with an experimental uncertainty in temperature as large as $200 \mathrm{~K}$ in flame conditions. The measured temperatures (see Fig. S3 in the Supplemental Material) in the different investigated flames are similar at the same positions, especially in the reaction zone where the intermediates are formed and depleted. Therefore the influences of temperature difference are excluded in the following discussion.

To have a clear understanding of the reaction patterns, schemes of the reaction network for the neat $\mathrm{C}_{2} \mathrm{H}_{6}$ and DMM flames are established in Fig. 2 based on the rate of production (ROP) analysis of specific species by integrating the ROP coefficients along the entire flame range. The reaction network for DMC under similar conditions was discussed in our previous study [19], which is provided as Fig. $\mathbf{S 4}$ in the Supplemental material. For $\mathrm{C}_{2} \mathrm{H}_{6}$ flame, the fuel is completely consumed through hydrogen abstractions, and the subsequent dehydrogenation process $\mathrm{C}_{2} \mathrm{H}_{5} \rightarrow \mathrm{C}_{2} \mathrm{H}_{4} \rightarrow \mathrm{C}_{2} \mathrm{H}_{3}$ $\rightarrow \mathrm{C}_{2} \mathrm{H}_{2}$ is the dominating pathway of the $\mathrm{C}_{2}$ species. Recombination with $\mathrm{C}_{1}$ species and oxidation pathways are also important and yield larger hydrocarbons and oxygenated intermediates, respectively. For DMM and DMC flames, hydrogen abstractions dominant the fuel consumption, while the unimolecular decompositions, including bond fissions and eliminations, also have remarkable (up to $40 \%$ ) contributions. The most important unimolecular decomposition pathway for DMM is the one yielding methanol $\left(\mathrm{CH}_{3} \mathrm{OH}\right)$, formyl $(\mathrm{HCO})$ and methyl $\left(\mathrm{CH}_{3}\right)$, which is actually a two-step process, i.e. DMM produces $\mathrm{CH}_{3} \mathrm{OH}$ and $\mathrm{CH}_{3} \mathrm{OCH}$ through a three-membered $\mathrm{H}$ atom transfer process, and at a much faster pace the reactive carbine $\mathrm{CH}_{3} \mathrm{OCH}$ decomposes to $\mathrm{HCO}$ and $\mathrm{CH}_{3}$. While for DMC the $\mathrm{CO}_{2}$ elimination through a four-membered transition state is the major unimolecular pathway. The oxygenated intermediates, methyl formate $\left(\mathrm{CH}_{3} \mathrm{OCHO}\right)$ and dimethyl ether $\left(\mathrm{CH}_{3} \mathrm{OCH}_{3}, \mathrm{DME}\right)$ are produced in the primary reactions of DMM and DMC, respectively.

ROP analysis of the fuel consumption was also performed in the entire range of the blended flames. According to relevant ROP analyzed results, when progressively increasing the addition amount of DMM (or DMC), no obvious changes can be observed in the decomposition pathways of 
individual fuels, which are still dominated by the hydrogen abstractions as mentioned above. This indicates that the fuel consumptions are barely affected by the fuel composition in the studied flames.
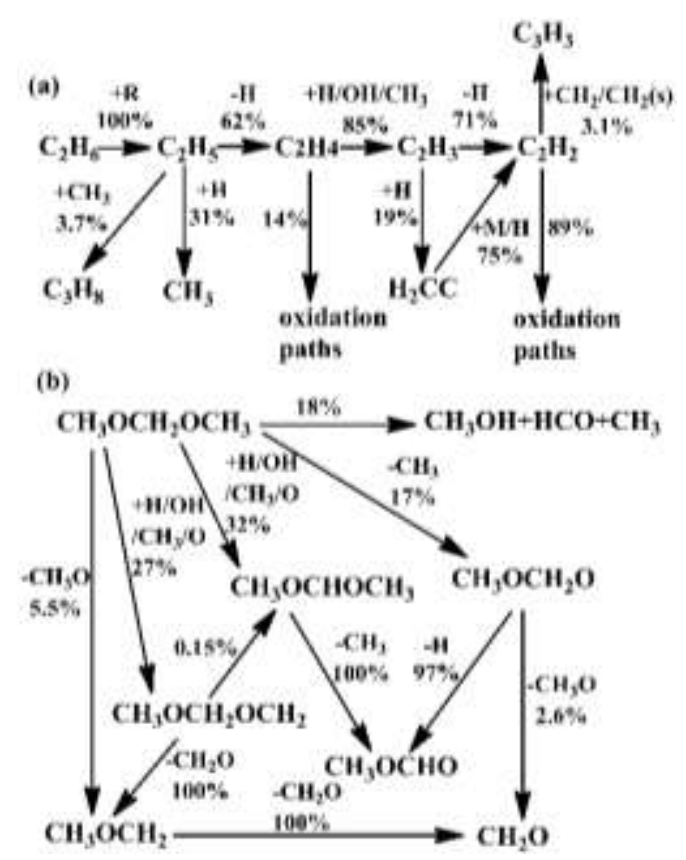

Fig. 2. Reaction pathways based on ROP analysis in the entire flame range for (a) $\mathrm{C}_{2} \mathrm{H}_{6}$ and (b) DMM in their neat fuel-rich premixed flames. The numbers are percent contributions to the consumption of the species on the source side of the arrow.

\subsection{Intermediates and harmful emissions}

The experimental measurements of the chemical compositions for separate flames can provide an overview of the species pool. Most of the detected species are shared in all investigated flames and no other species were observed in the blended series beyond the combined species pools of individual neat flames. However, the concentrations for specific species vary in a wide range for different flames. Figure 3 summarizes the experimental and simulated peak mole fractions for several crucial intermediates including methyl $\left(\mathrm{CH}_{3}\right)$, acetylene $\left(\mathrm{C}_{2} \mathrm{H}_{2}\right)$, ethylene $\left(\mathrm{C}_{2} \mathrm{H}_{4}\right)$, propargyl $\left(\mathrm{C}_{3} \mathrm{H}_{3}\right), \mathrm{C}_{6} \mathrm{H}_{6}$, formaldehyde $\left(\mathrm{CH}_{2} \mathrm{O}\right)$, acetaldehyde $\left(\mathrm{CH}_{3} \mathrm{CHO}\right)$, methyl formate $\left(\mathrm{CH}_{3} \mathrm{OCHO}\right)$ and dimethyl ether $\left(\mathrm{CH}_{3} \mathrm{OCH}_{3}\right)$. For each of the above species in the two flame series blended respectively with DMM and DMC, the mole fraction variation trends are compared. All the model predictions are within the experimental error limits. 

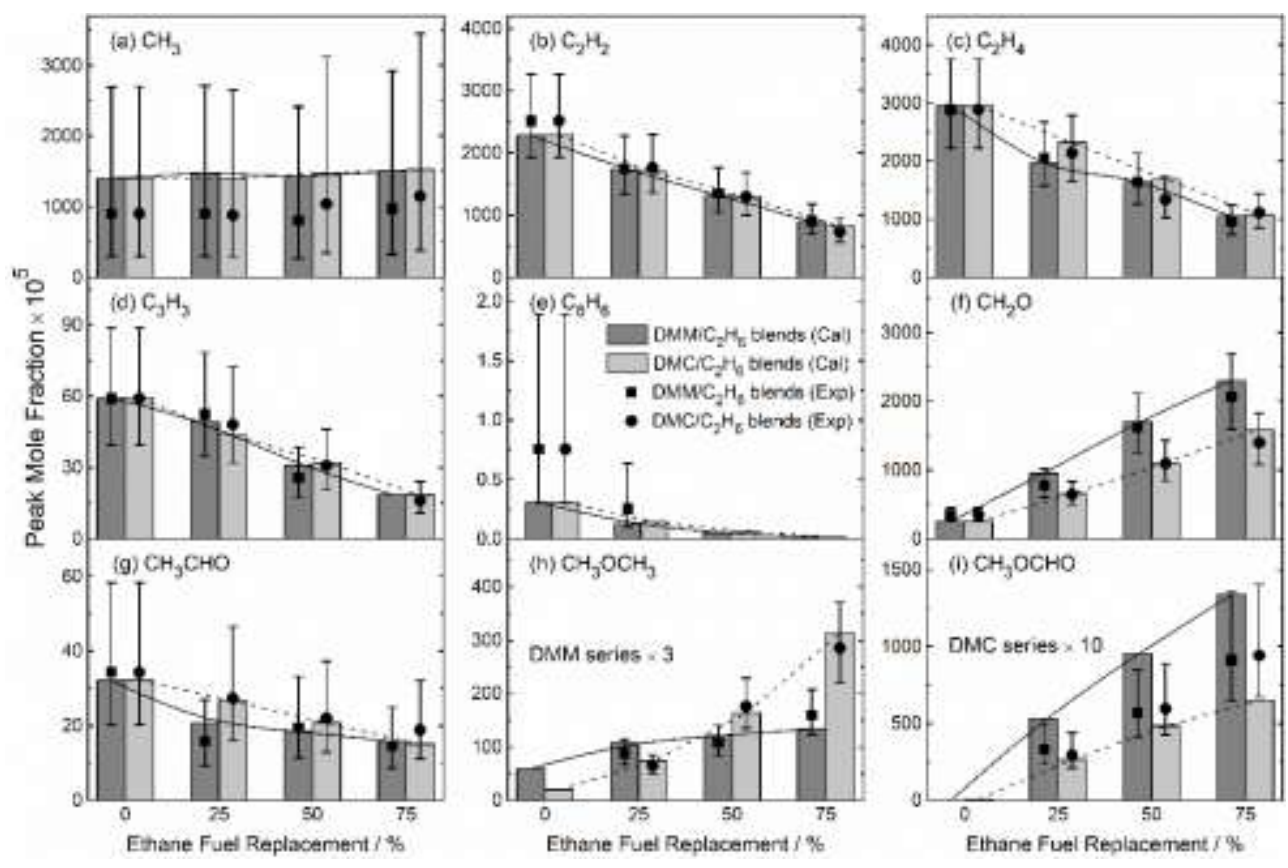

Fig. 3. Peak mole fractions (multiplied by $10^{5}$ ) of several crucial intermediates in different blended flames. Symbols with error bars: measurements with corresponding estimated uncertainties; Bars: predictions. The lines connecting the bars only serve as guides of the variation trends.

As shown in Fig.3(a) the concentrations of $\mathrm{CH}_{3}$ almost stay constant in the different flames, which could be affiliated to the numerous reactions involving $\mathrm{CH}_{3}$. The $\mathrm{ROP}$ analysis reveals that in the neat $\mathrm{C}_{2} \mathrm{H}_{6}$ flame, $\mathrm{CH}_{3}$ formation is dominated by the $\mathrm{C}_{2} \mathrm{H}_{5}+\mathrm{H}$ reaction (see Fig. 1), while the contributions of the $\beta$-scissions of $\mathrm{CH}_{3} \mathrm{OCH}_{2}$ and $\mathrm{CH}_{3} \mathrm{OCO}$ radicals become obvious when respectively adding DMM and DMC. Besides the oxidation by $\mathrm{O}$ and $\mathrm{OH}$, the self-recombination of $\mathrm{CH}_{3}$ plays a role in its consumption in the blended flames. For all $\mathrm{C}_{2}$ and larger hydrocarbons, obvious declining trends can be observed in the peak mole fractions when increasing the portion of DMM (or DMC). For $\mathrm{C}_{2} \mathrm{H}_{2}$ and $\mathrm{C}_{2} \mathrm{H}_{4}$, with significant levels reaching the magnitude of $10^{4} \mathrm{ppm}$, the peak concentrations almost linearly decrease. To facilitate the discussion, a definition of "volume effects" is provided first. Assuming that DMM in the blended series is replaced by argon with the $\mathrm{C} / \mathrm{O}$ ratio kept at 0.50 , chemical structures of the argon diluent ethane flame series are simulated with temperature profiles in corresponding blended flames. The mole fraction distributions of $\mathrm{C}_{2} \mathrm{H}_{4}$ in these flames are presented in Fig. 4 with the peak mole fractions shown in the inset. As a reference, simulated $\mathrm{C}_{2} \mathrm{H}_{4}$ peak mole fractions in DMM blended flame series are also 
presented. It can be noted that $\mathrm{C}_{2} \mathrm{H}_{4}$ peak mole fraction variations in the two flame series almost coincide. Therefore when adding DMM to the base ethane flame, DMM acts almost like a dilution gas, leading to the reduced level of $\mathrm{C}_{2} \mathrm{H}_{4}$. Such diluent effects of DMM in respect of $\mathrm{C}_{2} \mathrm{H}_{4}$ concentration is defined as "volume effects" in the present study. By conducting similar model analysis, it is proven that linear declines of $\mathrm{C}_{2}$ intermediates in both DMM and DMC blended series are resulted from "volume effects". That is because $\mathrm{C}_{2}$ species can hardly be directly formed through decomposition of DMM (or DMC) due to the absence of carbon-carbon (C-C) bonds in both oxygenates, but can be easily formed through the above-mentioned dehydrogenation process of $\mathrm{C}_{2} \mathrm{H}_{6}$.

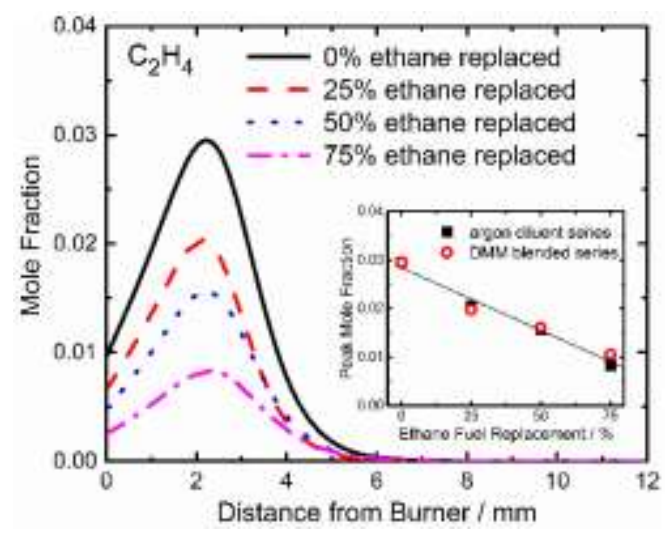

Fig.4. Model predicting $\mathrm{C}_{2} \mathrm{H}_{4}$ mole fraction profiles in neat argon diluent ethane flames, for each of which the initial ethane concentration, $\mathrm{C} / \mathrm{O}$ ratio and the temperature profile are kept the same with those of the corresponding DMM blended flame. Peak mole fractions in the argon diluent and DMM blended series are shown in the inset.

The self-recombination of $\mathrm{C}_{3} \mathrm{H}_{3}$, a resonantly stabilized radical, has been well established as a key route of benzene formation in combustion processes of most acyclic hydrocarbons [28]. ROP analysis was performed for $\mathrm{C}_{3} \mathrm{H}_{3}$ in each flame, and the results for the $\mathrm{C}_{2} \mathrm{H}_{6} / \mathrm{DMM}$ blends are shown in Fig. 5 while those for the $\mathrm{C}_{2} \mathrm{H}_{6} / \mathrm{DMC}$ series are provided in Fig. S5 in the Supplemental Material. In all flames, the recombination of $\mathrm{C}_{2} \mathrm{H}_{2}$ with methylene radicals $\left[\mathrm{CH}_{2}\right.$ and $\left.\mathrm{CH}_{2}(\mathrm{~s})\right]$ is the principal source of $\mathrm{C}_{3} \mathrm{H}_{3}$ which can combine with $\mathrm{CH}_{2}$ to produce larger hydrocarbons, otherwise break down through hydrogen abstractions by $\mathrm{OH}$ or oxidization by $\mathrm{O}$. When progressively adding DMM (or DMC), the relative importance of recombination is reduced while the abstraction and oxidation reactions contribute more to $\mathrm{C}_{3} \mathrm{H}_{3}$ consumption, which is consistent with the enhanced 
$\mathrm{OH}$ concentrations, as shown in Fig. S6. In addition, plenty of $\mathrm{O}$ atoms would be introduced to the mixtures when adding the oxygen-containing compounds. As a consequence, $\mathrm{C}_{6} \mathrm{H}_{6}$ was only detected in the base $\mathrm{C}_{2} \mathrm{H}_{6}$ flame and the blended one with $25 \%$ DMM addition, as demonstrated in Fig. 3(e). The modeled peak concentration of $\mathrm{C}_{6} \mathrm{H}_{6}$ drops under the ppm magnitude when about 50\% ethane is replaced by DMM and DMC, respectively. The approximately quadratic decline might be attributed to the linear decrease of $\mathrm{C}_{3} \mathrm{H}_{3}$, whose recombination contribute to the majority of $\mathrm{C}_{6} \mathrm{H}_{6}$ formation.

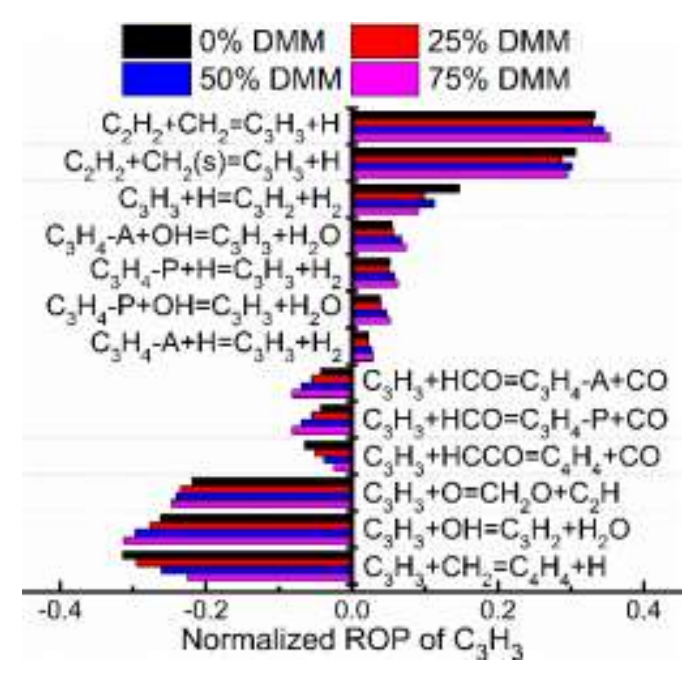

Fig. 5. Normalized ROP analysis of $\mathrm{C}_{3} \mathrm{H}_{3}$ in the $\mathrm{C}_{2} \mathrm{H}_{6} / \mathrm{DMM}$ blended flame series.

The peak concentrations of all the mentioned unsaturated hydrocarbons show similar decreasing trends in the DMM and DMC blended series. This suggests that the same extent of reduction can be achieved with the equal addition amount (by mole fraction) of DMM and DMC. Recognizing that two and three oxygen atoms are imbedded in the molecular structures of DMM and DMC, respectively, the oxygen atoms in DMM are therefore more efficiently utilized in reducing the soot/PAH formation. In the practical application, oxygenated additives are usually blended to the diesel fuel by liquid volume fraction. With the same liquid-volume addition, the molar amount of DMM and DMC is almost identical (113:119) with the basic physical properties for the two oxygenates (DMM: $0.856 \mathrm{~g} / \mathrm{cm} 3,76.10 \mathrm{~g} / \mathrm{mol}$; DMC: $1.069 \mathrm{~g} / \mathrm{cm} 3,90.07 \mathrm{~g} / \mathrm{mol}$ ) taken into consideration. Furthermore, with the higher heat value (1.702 MJ/mol for DMM and 1.215 $\mathrm{MJ} / \mathrm{mol}$ for DMC), DMM might be a better choice for practical use. 
The increasing emission of oxygenated pollutants is an unavoidable problem when putting oxygenated fuels to practical use. Two simple aldehydes, formaldehyde $\left(\mathrm{CH}_{2} \mathrm{O}\right)$ and acetaldehyde $\left(\mathrm{CH}_{3} \mathrm{CHO}\right)$ were detected in all flames, whose peak mole fractions are presented in Fig. 3 (f)-(g). The extremely high concentrations (over $10^{4} \mathrm{ppm}$ ) of $\mathrm{CH}_{2} \mathrm{O}$ in the blended flames can be explained by the reaction patterns of DMM and DMC. As mentioned above, the hydrogen abstractions dominate the consumption of DMM and DMC in flame conditions, and when the primary hydrogen atoms in DMM and DMC are abstracted, the corresponding fuel radicals, $\mathrm{CH}_{3} \mathrm{OCH}_{2} \mathrm{OCH}_{2}$ and $\mathrm{CH}_{3} \mathrm{OC}(=\mathrm{O}) \mathrm{OCH}_{2}$ subsequently break down through $\beta$-scissions yielding $\mathrm{CH}_{2} \mathrm{O}$. The peak mole fractions of $\mathrm{CH}_{2} \mathrm{O}$ in both blended series linearly increase with the portion of DMM (or DMC), at a faster pace in the DMM series. This behavior can be traced back to the $\mathrm{C}(=\mathrm{O})$ imbedded $\mathrm{DMC}$ that cannot participate in the formation of $\mathrm{CH}_{2} \mathrm{O}$. As a consequence the peak mole fraction of $\mathrm{CH}_{3} \mathrm{CHO}$ decreases when increasing the amount of DMM (or DMC). According to the results of relevant ROP analysis, the oxidation of $\mathrm{C}_{2} \mathrm{H}_{5}$ and isomerization of ethenol $\left(\mathrm{C}_{2} \mathrm{H}_{3} \mathrm{OH}\right)$ are the two principal sources of $\mathrm{CH}_{3} \mathrm{CHO}$ formation and $\mathrm{C}_{2} \mathrm{H}_{3} \mathrm{OH}$ originates nearly exclusively from the oxidation of $\mathrm{C}_{2} \mathrm{H}_{4}$ by $\mathrm{OH}$ according to relevant ROP-analyzed results. Both $\mathrm{C}_{2} \mathrm{H}_{5}$ and $\mathrm{C}_{2} \mathrm{H}_{4}$ are crucial intermediates in the consumption paths of $\mathrm{C}_{2} \mathrm{H}_{6}$. Furthermore, because of the absence of $\mathrm{C}-\mathrm{C}$ bonds in the molecular structure of DMM and DMC, no fuel-related reactions directly contribute to the formation of $\mathrm{CH}_{3} \mathrm{CHO}$. Therefore the reduction of $\mathrm{CH}_{3} \mathrm{CHO}$ concentrations can be mainly attributed to the lower initial content of $\mathrm{C}_{2} \mathrm{H}_{6}$ in the fuel mixture. Two oxygenated intermediates, $\mathrm{CH}_{3} \mathrm{OCHO}$ and $\mathrm{CH}_{3} \mathrm{OCH}_{3}$, are abundant in DMM and DMC blended series, respectively. Their peak mole fractions increase linearly with the amount of added oxygenates. This trend can be traced back to the reaction pathways of the two oxygenates. The radical $\mathrm{CH}_{3} \mathrm{OCHOCH}_{3}$, formed from the secondary $\mathrm{H}$ atom abstracted from DMM, breaks down through the energy-favored $\beta$-scission, simultaneously producing $\mathrm{CH}_{3} \mathrm{OCHO}$ and $\mathrm{CH}_{3}$. In the case of $\mathrm{DMC}, \mathrm{CH}_{3} \mathrm{OCH}_{3}$ can be directly released from the $\mathrm{CO}_{2}$ elimination $\left(\mathrm{CH}_{3} \mathrm{OC}(=\mathrm{O}) \mathrm{OCH}_{3}=\mathrm{CH}_{3} \mathrm{OCH}_{3}+\mathrm{CO}_{2}\right)$. These two species were not observed in the neat $\mathrm{C}_{2} \mathrm{H}_{6}$ flame without direct formation pathways. Influences of $\mathrm{C}_{2} \mathrm{H}_{6}$ initial 
concentration on $\mathrm{CH}_{3} \mathrm{OCHO}$ and $\mathrm{CH}_{3} \mathrm{OCH}_{3}$ peak mole fractions can also be attributed to "volume effects" as mentioned previously. To be more general, when a specific intermediate is predominantly produced from the consumption of only one component in a binary hydrocarbon/oxygenate fuel mixture, the other fuel component acts almost like a dilution, reactions of which could have negligible effects in respect of that intermediate.

It can be noted in Table 1 that in the present experiments at the fixed $\mathrm{C} / \mathrm{O}$ ratio of 0.50 , because of the altered fuel composition, equivalence ratio covered a range of 1.74-1.94 and 1.74 1.93 in the DMM and DMC series, respectively. Therefore concerns might arise that the observed variations might be attributed to the change in equivalence ratios, rather than the incrementally changed fuel composition. To address this issue, model simulations were performed for both blended flame series at the fixed equivalence ratios of 1.84 , which was actually the mid-value of the equivalence ratio variation ranges so the similarity of the flames in the same series could be ensured. For examples, the peak mole fractions of $\mathrm{C}_{2} \mathrm{H}_{2}$ and $\mathrm{CH}_{2} \mathrm{O}$ in the DMM series predicted by the model are illustrated in Fig. 6. Corresponding peak mole fractions at the fixed C/O ratio of 0.50 (the conditions of the current study) are also presented as a reference. According to the results, the similar linear decrease in $\mathrm{C}_{2} \mathrm{H}_{2}$ and increase in $\mathrm{CH}_{2} \mathrm{O}$ concentrations can be captured when either parameter is fixed. This behavior indicates that the observed variation patterns of the species concentrations are indeed brought by the blending. 


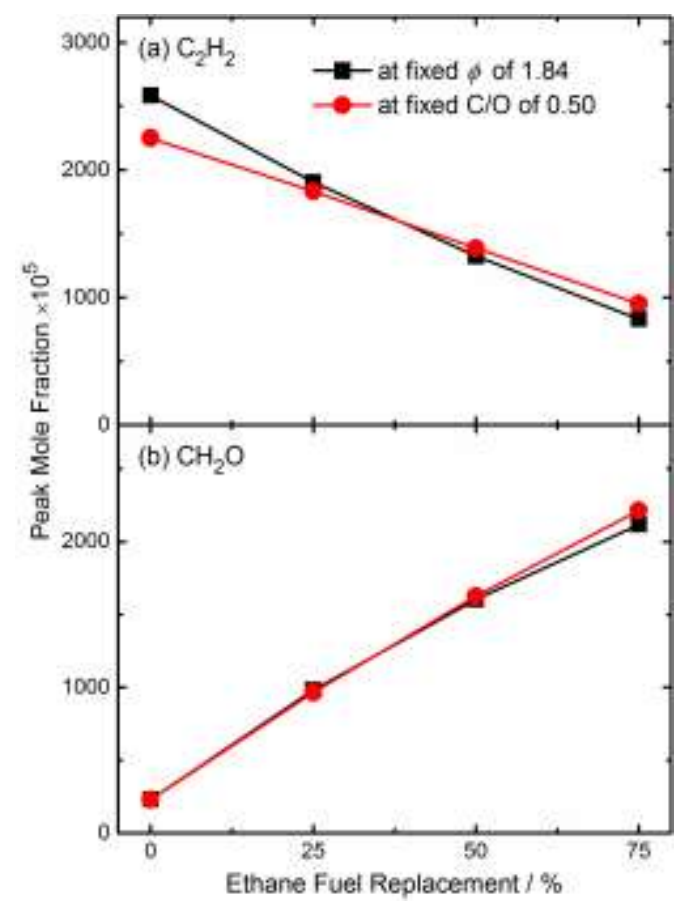

Fig. 6. Model predicting peak mole fractions in the $\mathrm{C}_{2} \mathrm{H}_{6} / \mathrm{DMM}$ blended flame series at fixed $\phi$ of 1.84 and fixed $\mathrm{C} / \mathrm{O}$ of 0.50 .

\section{Conclusion}

Chemical structures of two series of ethane-DMM (or DMC) blended flames with incrementally varying fuel composition were measured with the photoionization molecular beam mass spectrometry. A kinetic model was constructed and tested with the current measurements. The validated model and the experimental results were then used to explore the possible interactions among the radical pool and reaction networks, with focus on the harmful emissions. Both oxygenates (DMM and DMC) are effective in reducing unsaturated hydrocarbons because C-C bonds are absent from their molecular structures. With equal amount (by mole fraction) of DMM and DMC addition, the unsaturated hydrocarbons are reduced to almost the same extent. As two and three oxygen atoms are imbedded in DMM and DMC, respectively, DMM could be the better choice as a soot/PAH inhibitor in the perspective of $\mathrm{O}$ atoms usage efficiency. Both oxygenated fuels enhance the formation of $\mathrm{CH}_{2} \mathrm{O}$, whereas DMM has a more remarkable effect than DMC. This could be attributed to the fact that $\mathrm{CH}_{2} \mathrm{O}$ can be directly yielded from the $\beta$-scissions of the fuel radicals $\left[\mathrm{CH}_{3} \mathrm{OCH}_{2} \mathrm{OCH}_{2}\right.$ and $\left.\mathrm{CH}_{3} \mathrm{OC}(=\mathrm{O}) \mathrm{OCH}_{2}\right]$ formed through hydrogen abstractions. The observed linear variations in species concentrations when progressively increasing the addition 
amount of either oxygenate are mainly the result of "volume effects", instead of strong chemical interactions.

\section{Acknowledgements}

This work is supported by the National Natural Science Foundation of China (91541113, U1332208). NH and KM are supported by the U.S. Department of Energy (USDOE), Office of Basic Energy Sciences (BES) under Grant No. DE-AC04-94-AL85000. We thank the expert technical assistance of Paul Fugazzi and model analysis assistance of Shuang Li. The Advanced Light Source is supported by the Director, Office of Science, BES, USDOE under Contract No. DE-AC02-05CH11231. Sandia is a multi-program laboratory operated by Sandia Corporation, a Lockheed Martin Company, for the National Nuclear Security Administration under contract DE-AC04-94-AL85000. 


\section{References}

[1] C.K. Westbrook, W.J. Pitz, H.J. Curran, J. Phys. Chem. A 110 (2006) 6912-6922.

[2] K. Kohse-Höinghaus, P. Oßwald, T.A. Cool, T. Kasper, N. Hansen, F. Qi, C.K. Westbrook, P.R. Westmoreland, Angew. Chem. Int. Ed. 49 (2010) 3572-3597.

[3] K. Hoon Song, P. Nag, T.A. Litzinger, D.C. Haworth, Combust. Flame 135 (2003) 341-349.

[4] C. Renard, P. Van Tiggelen, J. Vandooren, Proc. Combust. Inst. 29 (2002) 1277-1284.

[5] V. Dias, J. Vandooren, Combust. Flame 158 (2011) 848-859.

[6] J. Wang, U. Struckmeier, B. Yang, T.A. Cool, P. Osswald, K. Kohse-Höinghaus, T. Kasper, N. Hansen, P.R. Westmoreland, J. Phys. Chem. A 112 (2008) 9255-9265.

[7] K. Kohse-Höinghaus, P. Oßwald, U. Struckmeier, T. Kasper, N. Hansen, C.A. Taatjes, J. Wang, T.A. Cool, S. Gon, P.R. Westmoreland, Proc. Combust. Inst. 31 (2007) 1119-1127.

[8] N. Hansen, M. Braun-Unkhoff, T. Kathrotia, A. Lucassen, B. Yang, Proc. Combust. Inst. 35 (2015) 771-778.

[9] M. Braun-Unkhoff, N. Hansen, T. Methling, K. Moshammer, B. Yang, Proc. Combust. Inst. (2016) http://dx.doi.org/10.1016/j.proci.2016.1005.1029.

[10] G. Chen, W. Yu, J. Fu, J. Mo, Z. Huang, J. Yang, Z. Wang, H. Jin, F. Qi, Combust. Flame 159 (2012) 2324-2335.

[11] V. Dias, H.M. Katshiatshia, H. Jeanmart, Combust. Flame 161 (2014) 2297-2304.

[12] N. Miyamoto, H. Ogawa, N.M. Nurun, K. Obata, T. Arima, SAE Tech. Pap. 980506, 1998.

[13] H.J. Curran, E.M. Fisher, P.A. Glaude, N.M. Marinov, W. Pitz, C. Westbrook, D. Layton, P.F. Flynn, R.P. Durrett, A. Zur Loye, SAE Tech. Pap. 2001-01-0653, 2001.

[14] T.C. Zannis, D.T. Hountalas, D.A. Kouremenos, SAE Tech. Pap. 2004-01-0097, 2001.

[15] L. Rubino, M.J. Thomson, SAE Tech. Pap. 1999-01-3589, 1999.

[16] C.A. Daly, J.M. Simmie, P. Dagaut, M. Cathonnet, Combust. Flame 125 (2001) 1106-1117.

[17] P.A. Glaude, W.J. Pitz, M.J. Thomson, Proc. Combust. Inst. 30 (2005) 1111-1118.

[18] V. Dias, X. Lories, J. Vandooren, Combust. Sci. Technol. 182 (2010) 350-364.

[19] W. Sun, B. Yang, N. Hansen, C.K. Westbrook, F. Zhang, G. Wang, K. Moshammer, C.K. Law, Combust. Flame 164 (2016) 224-238.

[20] T.A. Cool, A. Mcilroy, F. Qi, P.R. Westmoreland, L. Poisson, D.S. Peterka, M. Ahmed, Rev. Sci. Instrum. 76 (2005) 094102.

[21] N. Hansen, T.A. Cool, P.R. Westmoreland, K. Kohse-Höinghaus, Prog. Energy Combust. Sci. 35 (2009) 
168-191.

[22] A. Mcilroy, T.D. Hain, H.A. Michelsen, T.A. Cool, Proc. Combust. Inst. 28 (2000) 1647-1653.

[23] S. Dooley, F. Dryer, B. Yang, J. Wang, T. Cool, T. Kasper, N. Hansen, Combust. Flame 158 (2011) 732-741.

[24] U. Struckmeier, P. Oßwald, T. Kasper, L. Böhling, M. Heusing, M. Köhler, A. Brockhinke, K. Kohse-Höinghaus, Z. Phys. Chem. 223 (2009) 503-537.

[25] V. Gururajan, F.N. Egolfopoulos, K. Kohse-Höinghaus, Proc. Combust. Inst. 35 (2015) 821-829.

[26] W.K. Metcalfe, S.M. Burke, S.S. Ahmed, H.J. Curran, Int. J. Chem. Kinet. 45 (2013) 638-675.

[27] W. Li, M.E. Law, P.R. Westmoreland, T. Kasper, N. Hansen, K. Kohse-Höinghaus, Combust. Flame 158 (2011) 2077-2089.

[28] J.A. Miller, S.J. Klippenstein, J. Phys. Chem. A 107 (2003) 7783-7799.

[29] L.B. Harding, S.J. Klippenstein, Y. Georgievskii, J. Phys. Chem. A 111 (2007) 3789-3801.

[30] Y. Georgievskii, J.A. Miller, S.J. Klippenstein, Phys. Chem. Chem. Phys. 9 (2007) 4259-4268.

[31] J.P. Senosiain, J.A. Miller, J. Phys. Chem. A 111 (2007) 3740-3747.

[32] R. Kee, F. Ruply, J. Miller, CHEMKIN-PRO, Reaction Design, Inc., San Diego, CA, 2008. 


\section{Figure captions:}

Fig.1. Comparison between experimental and simulated mole fractions of main intermediates in (a) the $50 \% \mathrm{C}_{2} \mathrm{H}_{6}+50 \%$ DMM flame and (b) the $50 \% \mathrm{C}_{2} \mathrm{H}_{6}+50 \%$ DMC flame.

Fig. 2. Reaction pathways based on ROP analysis in the entire flame range for (a) $\mathrm{C}_{2} \mathrm{H}_{6}$ and (b) DMM in their neat fuel-rich premixed flames. The numbers are percent contributions to the consumption of the species on the source side of the arrow.

Fig. 3. Peak mole fractions (multiplied by $10^{5}$ ) of several crucial intermediates in different blended flames. Symbols with error bars: measurements with corresponding estimated uncertainties; Bars: predictions. The lines connecting the bars only serve as guides of the variation trends.

Fig.4. Model predicting $\mathrm{C}_{2} \mathrm{H}_{4}$ mole fraction profiles in neat argon diluent ethane flames, for each of which the initial ethane concentration, $\mathrm{C} / \mathrm{O}$ ratio and the temperature profile is kept the same with that of the corresponding DMM blended flame. Peak mole fractions in the argon diluent and DMM blended series are shown in the inset.

Fig.5. Normalized ROP analysis of $\mathrm{C}_{3} \mathrm{H}_{3}$ in the $\mathrm{C}_{2} \mathrm{H}_{6} / D M M$ blended flame series.

Fig.6. Model predicting peak mole fractions in the $\mathrm{C}_{2} \mathrm{H}_{6} / \mathrm{DMM}$ blended flame series at fixed $\phi$ of 1.84 and fixed $\mathrm{C} / \mathrm{O}$ of 0.50 . 